\title{
Somatic genetic alterations in a large cohort of pediatric thyroid nodules
}

\author{
Barbora Pekova', Sarka Dvorakova', Vlasta Sykorova', Gabriela Vacinova', Eliska Vaclavikova', Jitka Moravcova', \\ Rami Katra ${ }^{2}$, Petr Vlcek ${ }^{3}$, Pavla Sykorova ${ }^{3}$, Daniela Kodetova ${ }^{4}$, Josef Vcelak ${ }^{1}$ and Bela Bendlova ${ }^{1}$ \\ 'Department of Molecular Endocrinology, Institute of Endocrinology, Prague 1, Czech Republic \\ 2Department of Ear, Nose and Throat, 2nd Faculty of Medicine, Charles University in Prague and Motol University Hospital, Prague 5, Czech Republic \\ ${ }^{3}$ Department of Nuclear Medicine and Endocrinology, 2nd Faculty of Medicine, Charles University in Prague and Motol University Hospital, Prague 5, \\ Czech Republic \\ ${ }^{4}$ Department of Pathology and Molecular Medicine, 2nd Faculty of Medicine, Charles University in Prague and Motol University Hospital, Prague 5, \\ Czech Republic
}

Correspondence should be addressed to B Pekova: bpekova@endo.cz

\begin{abstract}
There is a rise in the incidence of thyroid nodules in pediatric patients. Most of them are benign tissues, but part of them can cause papillary thyroid cancer (PTC). The aim of this study was to detect the mutations in commonly investigated genes as well as in novel PTC-causing genes in thyroid nodules and to correlate the found mutations with clinical and pathological data. The cohort of 113 pediatric samples consisted of 30 benign lesions and 83 PTCs. DNA from samples was used for next-generation sequencing to identify mutations in the following genes: HRAS, KRAS, NRAS, BRAF, IDH1, CHEK2, PPM1D, EIF1AX, EZH1

and for capillary sequencing in case of the TERT promoter. RNA was used for real-time PCR to detect RET/PTC1 and RET/PTC3 rearrangements. Total detection rate of mutations was 5/30 in benign tissues and 35/83 in PTCs. Mutations in RAS genes (HRAS G13R, KRAS G12D, KRAS Q61R, NRAS Q61R) were detected in benign lesions and HRAS Q61R and NRAS Q61K mutations in PTCs. The RET/PTC rearrangement was identified in 18/83 of PTCs and was significantly associated with higher frequency of local and distant metastases. The BRAF V600E mutation was identified in 15/83 of PTCS and significantly correlated with higher age of patients and classical variant of PTC. Germline variants in the genes IDH1, CHEK2 and PPM1D were found. In conclusion, RET/PTC rearrangements and BRAF mutations were associated with different clinical and histopathological features of pediatric PTC. RAS mutations were detected with high frequency in patients with benign nodules; thus, our results suggest that these patients should be followed up intensively.
\end{abstract}

\section{Key Words}

- papillary thyroid cancer

- pediatric

- mutations

- benign

- next-generation sequencing

\section{Introduction}

Thyroid nodules affect around $1 \%$ of the pediatric population. The incidence has been steadily increasing over the last decades, by approximately $1.1 \%$ per year worldwide $(1,2)$. Possible reasons for this increase are improvements in medical care including ultrasonography and fine-needle aspiration biopsy, environmental carcinogens, endocrine disruptors, inadequate iodine intake and exposure to radiation (3). Thyroid nodules have benign or malignant character. The risk of malignancy is higher in pediatric nodules compared with adults, 26 vs $7-15 \%(2,4)$.

Pediatric thyroid cancer is a rare disease occurring mostly in females than in males (1). The most common type is papillary thyroid cancer (PTC), which represents $90 \%$ or more of pediatric thyroid cancer (4). Medullary (MTC) and follicular thyroid cancer (FTC) are relatively rare. MTC is mostly familial than sporadic in children and adolescents. Poorly differentiated cancer and anaplastic

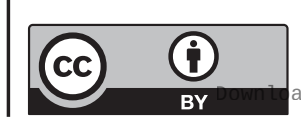

This work is licensed under a Creative Commons Attribution 4.0 International License. 
thyroid cancer (ATC) have only been identified in several pediatric patients $(5,6)$.

PTCs in children and adolescents are more aggressive than adult PTCs according to many studies $(7,8,9)$. On the other hand, they have better outcomes, a lower rate of dedifferentiation and a disease-specific mortality lower than $2 \%$ (10). Due to many differences between pediatric and adult PTCs, ATA guidelines specifically for children and adolescents were developed (4).

Differences between pediatric and adult PTCs are not only in clinical-pathological features, but also in genetic alterations. Main PTC-activating somatic mutations in the RAS, BRAF and TERT genes and RET/PTC rearrangements cause uncontrolled activation of MAPK and PI3K signaling pathways. It was reported that pediatric PTCs harbor more frequently rearrangements and less frequently point mutations than adult PTCs $(11,12)$. However, published studies have been performed only in a limited number of pediatric patients or on a low number of investigated genes.

In the Thyroid Cancer Genome Atlas (TCGA) project, genetic alterations of 496 PTCs were detected and mutations in the CHEK2, PPM1D and EIF1AX genes were identified as the novel PTC-causing genes. If these genes play a role in pediatric carcinogenesis is still unknown, because only nine pediatric patients were included in the TCGA project (13).

To the other genes that are associated with thyroid nodules, IDH1 and EZH1 genes belong. Mutations in the IDH1 gene are present in many different types of cancer, including PTC. Several variants have been revealed in the conserved part of the IDH1 gene with an association with follicular variant of PTC (14). In the EZH1 gene a hotspot Q571R mutation was detected that causes increased proliferation of thyroid cells (15). This mutation was found predominantly in benign thyroid nodules with follicular pattern and without RAS mutation (16).

The purpose of this study was to identify main genetic alterations in one of the largest pediatric cohorts of thyroid nodules. This study investigated not only commonly screened genes HRAS, KRAS, NRAS, BRAF, TERT, but also newly identified genes IDH1, CHEK2, PPM1D, EIF1AX and EZH1. From fusion genes the most common RET/PTC1 and RET/PTC3 rearrangements were tested.

\section{Material and methods}

\section{Patients and data collection}

The cohort consisted of 113 samples from 83 PTCs and 30 benign lesions. Samples were collected from pediatric patients who underwent surgery from 2003 to 2017 at the Department of Ear, Nose and Throat, 2nd Faculty of Medicine, Charles University and Motol University Hospital in Prague. The thyroid tumor samples were histologically evaluated. All the specimens were snapfrozen and stored at $-80^{\circ} \mathrm{C}$ until used for DNA and RNA isolation. Clinical and histopathological data were obtained from clinical and pathological records. Patients or their legal representatives signed an informed consent for genetic studies approved by the Ethics Committee of the Institute of Endocrinology.

\section{DNA and RNA extraction}

DNA and RNA isolations were performed using the AllPrep DNA/RNA/Protein Mini kit (Qiagen) according to the manufacturer's instructions. The concentration and purity of DNA and RNA was measured using a spectrophotometer (NanoPhotometer P330; Implen $\mathrm{GmbH}$, München, Germany) and a fluorometer (Qubit 2.0; Invitrogen). The RNA integrity was evaluated using a Bioanalyzer 2100 and Agilent RNA 6000 Nano Kit (Agilent Technologies).

\section{Next-generation sequencing}

The analyzed genes were HRAS (exons 2, 3), KRAS (exons 2, 3), NRAS (exons 2, 3), BRAF (exon 15), TERT (promoter), IDH1 gene (exons 4, 6), CHEK2 (exons 3, 4, 7, 11, 13), PPM1D (exons 1, 4, 5, 6), EIF1AX (exons 1, 2, 5, 6), EZH1 (exons 16, 17). Exons of RAS, BRAF, CHEK2, PPM1D, EIF1AX genes and the TERT promoter were selected for analysis because they were the most mutated regions in the TCGA study (13). Exons of IDH1 and EZH1 genes were chosen according to previous publications $(14,16)$. Exons were amplified using PCR with sequence-specific primers. The primer sequences and PCR conditions are available on request. The PCR products were purified using Agencourt AMPure (Beckman Coulter) and used for preparation of next-generation sequencing (NGS) libraries using Nextera XT Sequencing Kit (Illumina) according to the manufacturer's sample preparation protocol and modifications as described in our previous article (17). The NGS libraries were paired-end sequenced for 500 cycles by MiSeq Reagent kit v2 (Illumina) using MiSeq sequencer platform (Illumina).

All variants of the novel PTC-causing genes from TCGA study were also analyzed in DNA samples extracted from peripheral blood of the same patient to distinguish somatic and germline detected genetic changes.

This work is licensed under a Creative Commons Attribution 4.0 International License. ded from Bioscientifica.com at 04/26/2023 01:22:08PM 
The reference sequences of genes HRAS, KRAS, NRAS, BRAF, IDH1, CHEK2 and PPM1D were NM_005343.3, NM_033360.3,NM_002524.4,NM_004333.4,NM_005896.3, NM_007194.3 and NM_003620.3, respectively.

\section{Capillary sequencing}

The PCR products of TERT promoter were purified using Agencourt AMPure (Beckman Coulter), and then sequencing reaction using Quick Start Master Mix Kit with Dye Terminator Cycle Sequencing (Beckman Coulter) was performed. Products of the sequencing reaction were purified using Agencourt Clean SEQ Dye-Terminator Removal (Beckman Coulter). Capillary sequencing was performed by CEQ 8000 instrument (Beckman Coulter). Analyses were evaluated by CEQ 8000 software. The primer sequences and PCR conditions are available on request.

\section{Real-time PCR}

RNA was reverse transcribed into cDNA using random primers and AMV Reverse Transcriptase (Promega). Subsequently, cDNA was mixed with iQ SYBR Green Supermix (Bio-Rad) and sequence-specific primers and RET/PTC1 and RET/PTC3 detection was performed by Real-Time PCR (Light Cycler 480, Roche). Reaction conditions and primers were set according to our previous article (18). For cDNA quality control, the expression of housekeeping gene ( $\beta$-actin, $A C T B$ ) was tested in every sample. Analyses were evaluated by Light Cycler® 480 SW 1.5.1.

\section{Statistical analysis}

Statistical analysis was performed with $t$-test and Fisher's exact test. $P$ value $<0.05$ was considered as statistically significant.

\section{Results}

\section{Patient characteristics}

The study consisted of 113 specimens of pediatric patients with predominance of females (73.5\%). The age ranged 6-20 years at the time of diagnosis.

As detailed in Fig. 1 and Table 1, 30 samples of benign lesions were collected (nine solitary thyroid nodules, eight follicular adenomas, five multinodular goiters, five chronic lymphocytic thyroiditis, two thyroid cysts, one oncocytic adenoma). The cohort of benign patients had a mean age at diagnosis $14.7 \pm 2.6$ years and most of the group consisted of females (24/30). The half of the patients underwent hemithyroidectomy and the other half total thyroidectomy, and in two of them the lymph node dissection was performed. Multifocal nodules in six cases were noted.

Medical records of 83 patients with PTCs were studied for family history, another serious disease and radiation exposure before PTC diagnosis. Thyroid disease in family history had 25 patients. Except two, no other patient had thyroid cancer in family. Two patients had known previous history of radiation exposure. The first one was diagnosed with acute lymphoblastic leukemia and the therapeutic whole-body radio-exposition was prior to thyroid cancer diagnosis. The second patient was diagnosed with Hodgkin's lymphoma and was treated with chemotherapy and radiotherapy. One patient was diagnosed with Cowden syndrome, which is associated with a higher risk of thyroid cancer due to mutation in the PTEN gene.

Detailed patient's characteristics of the PTC cohort are summarized in Fig. 1 and Table 2. PTC patients were predominantly females (59/83). Total thyroidectomy was performed in 72 PTC cases and hemithyroidectomy in 11 PTC cases. Hemithyroidectomy was completed to total thyroidectomy in ten cases due to diagnosis of PTC. Mean size of tumor was $22.2 \pm 13.6 \mathrm{~mm}$. Microcarcinomas defined as tumors with diameter $10 \mathrm{~mm}$ or smaller were detected in 16/83 cases. The most common variant of PTC was follicular variant followed by the classical variant. Many rare variants such as columnar, clear cell, tall cell and diffuse sclerosing variant were identified. More than half PTCs were multifocal (46/83) and nearly half had extrathyroidal extension (37/83) and were classified as T3/T4 (38/83). Lymph node metastases were detected in $52 / 83$ and distant metastases in 10/83 cases. All distant metastases were affecting lungs. Most of the PTC patients (72/82) underwent radioactive iodine (RAI) treatment. One 7-year-old patient died from the disease after surgery and before RAI treatment. Maximum number of RAI ablations was 6 , which was used in two cases. The RAI treatment was applied in the first case during 9 years and in the second case during 11 years. In the first case, it was PTC with mix of classical, follicular and solid variant and in the second case, it was solid variant of PTC. Reoperations of lymph node metastases were performed in five patients; two of them underwent reoperations three times.

Median follow-up was 72 months (range 1-170 months). Thyreoglobulin (Tg) blood serum level

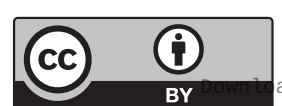

This work is licensed under a Creative Commons Attribution 4.0 International License. 

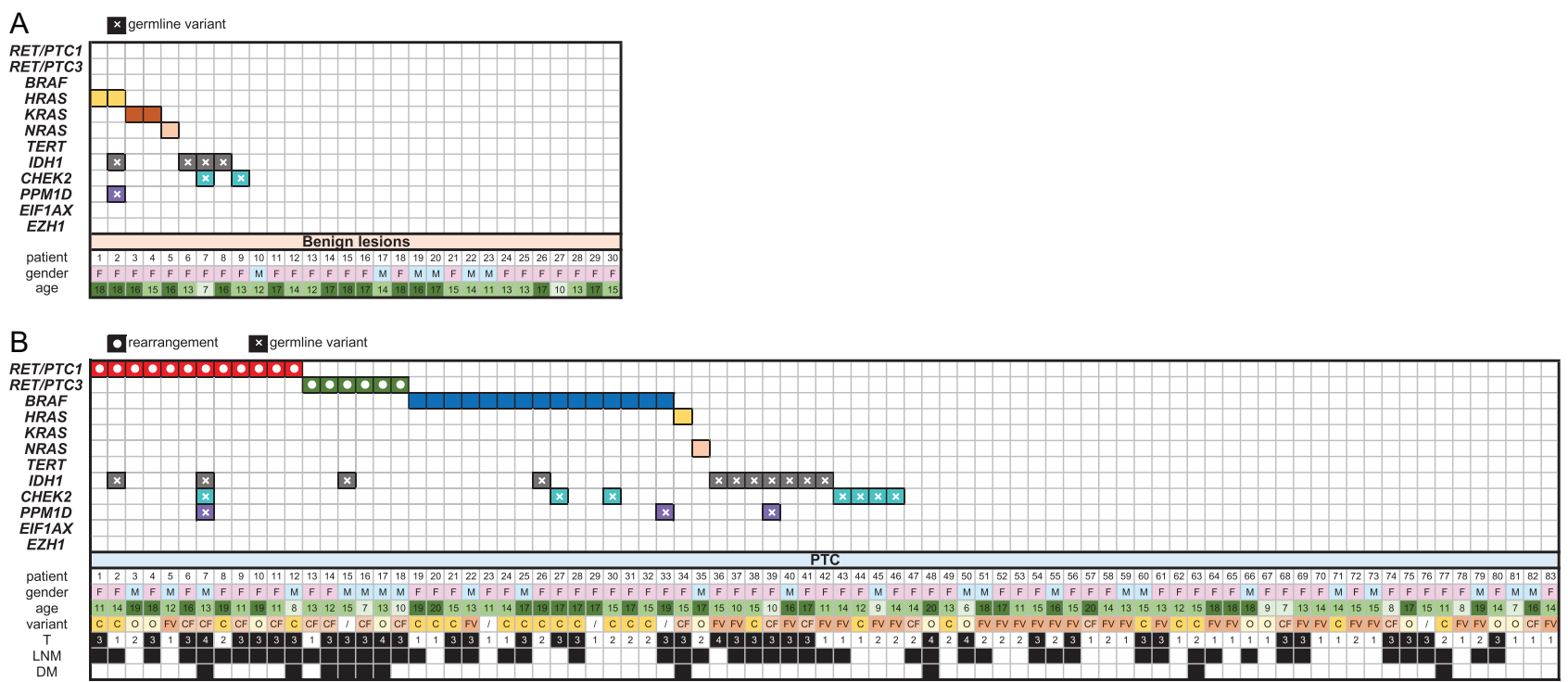

Figure 1

Tile plot of genetic alterations detected in patients with benign lesions (A) and with PTC (B). Clinical and pathological data as gender, age at diagnosis, histological variant, tumor stage, lymph node metastases and distant metastases are shown. C, classical variant; CF, classical and follicular variant; DM distant metastases; F, female; FV, follicular variant; LNM, lymph node metastases; M, male; O, other variant; PTC, papillary thyroid cancer; T, tumor size and extension.

and thyreoglobulin antibodies (a-Tg) were monitored for whole postoperative care. Remission was defined as a condition of the patient with any suspect object on ultrasound or whole-body scintigraphy, the Tg levels were lower than $1 \mu \mathrm{g} / \mathrm{L}$ and the a-Tg levels were not detectable. Recurrence and persistence were defined as a condition of a patient with malignant object or objects on ultrasound

Table 1 Characteristics of pediatric benign cohort.

Patients
Females
Males
Age at diagnosis (years, mean \pm S.D.)
Type of disease
Solitary thyroid nodule
Follicular adenoma
Multinodular goiter
Chronic lymphocytic thyroiditis
Thyroid cyst
Oncocytic adenoma
Surgery
Hemithyroidectomy - left lobe
Hemithyroidectomy - right lobe
Total thyroidectomy without LND
Total thyroidectomy with LND
Tissue characteristics
Mean \pm s.D. (mm)
Multifocality

\begin{tabular}{c}
$\begin{array}{c}\text { Pediatric benign cohort } \\
(n=30)\end{array}$ \\
\hline 24 \\
6 \\
$14.7 \pm 2.6$ \\
9 \\
8 \\
5 \\
5 \\
2 \\
1 \\
8 \\
7 \\
13 \\
2
\end{tabular}

$22.2 \pm 12.1$

6

LND, lymph node dissection. or whole-body scintigraphy at least 1 year after surgery or patient who entered remission and then malignant object was appeared. Biochemical persistence was defined as a condition of the patient with the level of Tg higher than $1 \mu \mathrm{g} / \mathrm{L}$ or detectable level of a-Tg with no evident tumor recurrence or persistence. Eight patients could not be classified due to short-term follow-up (range 0-12 months after surgery).

\section{Mutational analysis}

The detection rate of mutations in benign and malignant cohorts is noted in Table 3. The total detection rate of mutations in the cohort of benign tissues was $5 / 30$ and in the cohort of PTCs was $35 / 83$, of which RET/PTC rearrangement (18/83), BRAF V600E mutation (15/83) and RAS mutations (2/83) were identified (Fig. 1). All mutations in benign cohort were in RAS genes (Fig. 1). Mutations of RAS genes in benign lesions included HRAS G13R mutation found in one follicular adenoma with uncertain behavior and in one solitary thyroid nodule with oncocytic changes, KRAS G12D mutation in the multinodular goiter, KRAS Q61R mutation in the follicular adenoma and NRAS Q61R mutation in the multinodular goiter with oncocytic changes. Only two mutations in $R A S$ genes were identified in PTCs: HRAS Q61R and NRAS Q61K. NRAS Q61K mutation was found in tall cell variant of PTC and HRAS Q61R mutation in the mix of

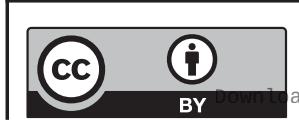

This work is licensed under a Creative Commons Attribution 4.0 International License. ded from Bioscientifica.com at 04/26/2023 01:22:08PM 
Table 2 Characteristics of pediatric PTC cohort.

\begin{tabular}{|c|c|}
\hline & Pediatric PTC $(n=83)$ \\
\hline \multicolumn{2}{|l|}{ Patients } \\
\hline Females & 59 \\
\hline Males & 24 \\
\hline Age at diagnosis (years, mean \pm S.D.) & $14.2 \pm 3.4$ \\
\hline History of radioexposure & 2 \\
\hline \multicolumn{2}{|l|}{ Tumor size } \\
\hline Mean \pm S.D. $(\mathrm{mm})$ & $22.2 \pm 13.6$ \\
\hline Microcarcinoma ( $\leq 10 \mathrm{~mm})$ & 16 \\
\hline \multicolumn{2}{|l|}{ Histological variant ${ }^{\mathrm{a}}$} \\
\hline Classical & 23 \\
\hline Classical and follicular & 16 \\
\hline Follicular & 27 \\
\hline Solid & 3 \\
\hline Classical, follicular and solid & 3 \\
\hline Diffuse sclerosing & 2 \\
\hline Columnar & 2 \\
\hline Tall cell & 1 \\
\hline Clear cell & 1 \\
\hline \multicolumn{2}{|l|}{ Pathological characteristics } \\
\hline Multifocality & 46 \\
\hline Extrathyroidal extension & 37 \\
\hline Intravascular invasion & 22 \\
\hline $\mathrm{T} 1 / \mathrm{T} 2$ classification & 45 \\
\hline T3/T4 classification & 38 \\
\hline Lymph node metastases (N) & 52 \\
\hline Distant metastases (M) & 10 \\
\hline Chronic lymphocytic thyroiditis & 42 \\
\hline \multicolumn{2}{|l|}{ Radioiodine therapy ${ }^{\mathrm{b}}$} \\
\hline Without radioiodine therapy & 9 \\
\hline One dose & 41 \\
\hline Two or more doses & 31 \\
\hline \multicolumn{2}{|l|}{ Follow-up ${ }^{c}$} \\
\hline Reoperation of recurrent metastases & 5 \\
\hline Remission & 49 \\
\hline Recurrence or persistence & 9 \\
\hline Biochemical persistence & 16 \\
\hline Disease-specific mortality & 1 \\
\hline
\end{tabular}

an five cases histological variant was not available; bin two cases radioiodine therapy records were not available; 'eight cases were not classified due to short-term follow-up.

PTC, papillary thyroid cancer.

classical and follicular variant of PTC. Both patients with $R A S$ mutation had lymph node metastases and multifocal carcinoma. The patient with HRAS mutation was diagnosed with Hodgkin's lymphoma three years prior to diagnosis of PTC. The tumor had very invasive character; intravascular invasion and lung metastases were detected.

Clinical-pathological features of RET/PTC and $B R A F$-positive patients are summarized and compared in Table 4. The most common mutation was the RET/PTC rearrangement detected in 18/83 PTCs, including RET/PTC1 in 11 and RET/PTC3 in 6 samples. In single case, novel RET/PTC rearrangement named RET/PTC1ex9, which included part of exon 9 of the RET gene, was also
Table 3 Comparison of detection rate of mutations in benign and malignant nodules.

\begin{tabular}{|c|c|c|c|}
\hline Mutation & Benign $(n=30)$ & Malignant $(n=83)$ & $P$ value \\
\hline HRAS G13R & 2 & 0 & \\
\hline HRAS Q61R & 0 & 1 & \\
\hline KRAS G12D & 1 & 0 & \\
\hline KRAS Q61R & 1 & 0 & \\
\hline NRAS Q61K & 0 & 1 & \\
\hline NRAS Q61R & 1 & 0 & \\
\hline RAS total & 5 & 2 & 0.014 \\
\hline$B R A F$ V600E & 0 & 15 & 0.010 \\
\hline TERT & NA & 0 & \\
\hline RET/PTC1 & 0 & 11 & \\
\hline RET/RET1ex9 & 0 & 1 & \\
\hline RET/PTC3 & 0 & 6 & \\
\hline RET/PTC total & 0 & 18 & 0.003 \\
\hline Total & 5 & 35 & 0.014 \\
\hline
\end{tabular}

NA, not analyzed. Bold indicates statistical significance.

identified (18). The ratio between females and males in RET/PTC-positive patients was lower compared to $B R A F$ positive patients, but not statistically significant $(P=0.070)$. Samples with RET/PTC rearrangement were significantly associated with mix of classical and follicular variant of PTC $(P=0.009)$ and higher frequency of lymph node metastases $(P=0.020)$ and distant metastases $(P=0.005)$. All six RET/PTC3-positive patients had lymph node metastases, four of these six patients had lung metastases and one patient died from disease. The BRAF V600E mutation was detected in 15/83 PTC samples. In $B R A F$ positive patients the mean age at the time of diagnosis was significantly higher than in $R E T / P T C$ positive patients $(P=0.012)$. The $B R A F$ mutation also correlates with the classical variant of PTC $(P<0.001)$. The number of patients, who underwent reoperation of recurrent lymph node metastases, was higher, but not significantly $(P=0.073)$. Five patients did not respond to RAI treatment because they did not accumulate RAI. Mutations in the BRAF gene and RET/PTC rearrangements were exclusively found in malignant samples.

The TERT promoter was analyzed only in malignant samples and no mutation was found.

Detected variants in the IDH1, CHEK2 and PPM1D genes are summarized in Fig. 1 and Table 5. Variants G105G and V178I in the IDH1 gene always co-occurred and were detected with comparable frequency 9/83 in malignant and 3/30 in benign samples. The third genetic variant in the IDH1 gene was Y183C. In the CHEK2 gene R117G substitution and T367Mfs*15 deletion was identified only in PTC samples. I157T variant was the most common variant in the CHEK2 gene and was found predominantly in malignant samples. L467F variant was

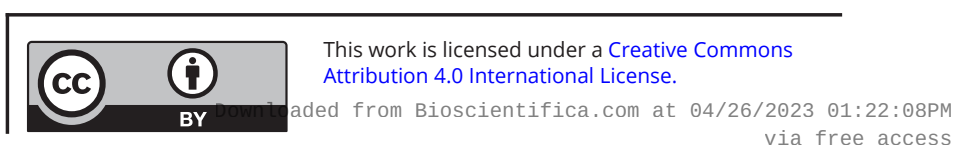


Table 4 The comparison of clinical and pathological features between RET/PTC- and BRAF-positive patients.

\begin{tabular}{|c|c|c|c|}
\hline & RET/PTC $(n=18)$ & $\overline{\boldsymbol{B R A F}}(n=15)$ & $P$ value \\
\hline \multicolumn{4}{|l|}{ Patients } \\
\hline Females/males & $10 / 8(1.25: 1)$ & $13 / 2(6.5: 1)$ & 0.070 \\
\hline $\begin{array}{l}\text { Age at diagnosis } \\
\text { (mean } \pm \text { S.D.) }\end{array}$ & $13.4 \pm 3.6$ & $16.3 \pm 2.4$ & 0.012 \\
\hline \multicolumn{4}{|l|}{ Tumor size } \\
\hline Mean \pm S.D. $(\mathrm{mm})$ & $29.6 \pm 18$ & $20 \pm 10.6$ & 0.079 \\
\hline $\begin{array}{l}\text { Microcarcinoma } \\
(\leq 10 \mathrm{~mm})\end{array}$ & 3 & 4 & 0.674 \\
\hline \multicolumn{4}{|l|}{ Histological variant ${ }^{a}$} \\
\hline Classical & 4 & 11 & $<0.001$ \\
\hline Classical and follicular & 8 & 0 & 0.009 \\
\hline Follicular & 1 & 1 & 1.000 \\
\hline Other & 4 & 0 & 0.121 \\
\hline \multicolumn{4}{|l|}{ Pathological characteristics } \\
\hline Multifocality & 11 & 8 & 0.733 \\
\hline $\begin{array}{l}\text { Extrathyroidal } \\
\text { extension }\end{array}$ & 12 & 6 & 0.170 \\
\hline Intravascular invasion & 7 & 3 & 0.283 \\
\hline $\mathrm{T} 1 / \mathrm{T} 2$ classification & 5 & 9 & 0.085 \\
\hline T3/T4 classification & 13 & 6 & \\
\hline $\begin{array}{l}\text { Lymph node } \\
\text { metastases }(\mathrm{N})\end{array}$ & 16 & 7 & 0.020 \\
\hline Distant metastases (M) & 6 & 0 & 0.005 \\
\hline $\begin{array}{l}\text { Chronic lymphocytic } \\
\text { thyroiditis }\end{array}$ & 9 & 4 & 0.284 \\
\hline \multicolumn{4}{|l|}{ Radioiodine therapy ${ }^{b}$} \\
\hline $\begin{array}{l}\text { Without radioiodine } \\
\text { therapy }\end{array}$ & 2 & 2 & 1.000 \\
\hline One dose & 8 & 5 & 0.725 \\
\hline Two or more doses & 8 & 7 & 1.000 \\
\hline \multicolumn{4}{|l|}{ Follow-upc } \\
\hline $\begin{array}{l}\text { Reoperation of } \\
\text { recurrent metastases }\end{array}$ & 0 & 3 & 0.073 \\
\hline Remission & 10 & 6 & 0.285 \\
\hline $\begin{array}{l}\text { Recurrence or } \\
\text { persistence }\end{array}$ & 1 & 3 & 0.295 \\
\hline $\begin{array}{l}\text { Biochemical } \\
\text { persistence }\end{array}$ & 6 & 5 & 1.000 \\
\hline $\begin{array}{l}\text { Disease-specific } \\
\text { mortality }\end{array}$ & 1 & 0 & 1.000 \\
\hline
\end{tabular}

aln three BRAF-positive cases and in one RET/PTC positive case histological variant was not available; bin one BRAF-positive case radioiodine therapy record was not available; ' cone BRAF-positive case was not classified due to short-term follow-up.

Bold indicates statistical significance.

detected only in one patient with follicular adenoma. In the PPM1D gene A152A variant was identified only in PTCs and I496V variant was detected in the benign solitary node together with variants of HRAS G13R and three variants G105G, V178I and Y183C in the IDH1 gene. The differences between malignant and benign cohorts were not statistically significant (Table 5). All variants identified in IDH1, CHEK2 and PPM1D genes were also tested in DNA from peripheral blood of the same patients that we had tissue and we revealed all variants as germline. No variants in genes EIF1AX and EZH1 were identified in malignant or in benign samples.

\section{Discussion}

Thanks to the development of NGS and using this technique in molecular genetics laboratories, it is possible to study the precise and comprehensive genetic landscape of pediatric thyroid nodules. It helps not only to increase detection rate, but also to identify new molecular markers or cancer gene predispositions. Several years ago, only small cohorts of pediatric patients and few selected numbers of genetic alterations were investigated. Recently, studies with larger cohorts of pediatric patients have appeared with enlarging the spectrum of investigated genetic mutations using NGS panels to find mutations or gene fusions $(12,19,20)$. Our study with the size of 113 samples of thyroid nodules is according to our best knowledge the largest pediatric cohort that was analyzed by NGS and provides very important genetic, clinical and pathological data. Unlike our study, in previous studies where NGS panels were also used, presented a limited number of pediatric PTC specimens that ranged from 13 to 25 (12, $19,20)$. On the other hand, NGS panels included more genes (14-250) in these studies $(12,19,20)$. Moreover, mutations in genes TET, TSHR (12) and CDKN2A (19) and rearrangements of $A L K, N T R K 1, N T R K 3, P P A R \gamma$ genes were revealed $(12,20)$, besides point mutations in the genes identified also in our study.

Mutations in RAS genes occur in malignant and benign pediatric thyroid nodules overall with very low frequency $(20,21,22,23)$. In our cohort, NRAS and HRAS mutations were detected with no other co-mutation in PTCs with aggressive character, and surprisingly, five $R A S$ positive samples were identified in benign lesions. Clinical impact and prognostic importance of RAS mutations is not clearly established, because they appear in follicular adenoma and also in ATC. The risk of malignancy varies among RAS genes (HRAS 92\%, NRAS 74\%, KRAS 61\%) in adult population (24). When we consider that pediatric patients have overall higher risk of malignancy than adults, the numbers could be even higher. In our benign cohort, oncocytic changes or uncertain behaviour were identified in HRAS and NRAS-positive samples, but not in KRAS-positive samples. RAS mutations could play a role in early cancerogenesis (25). It implies that the pediatric patients with benign lesions harboring RAS mutations should be more intensively followed. 

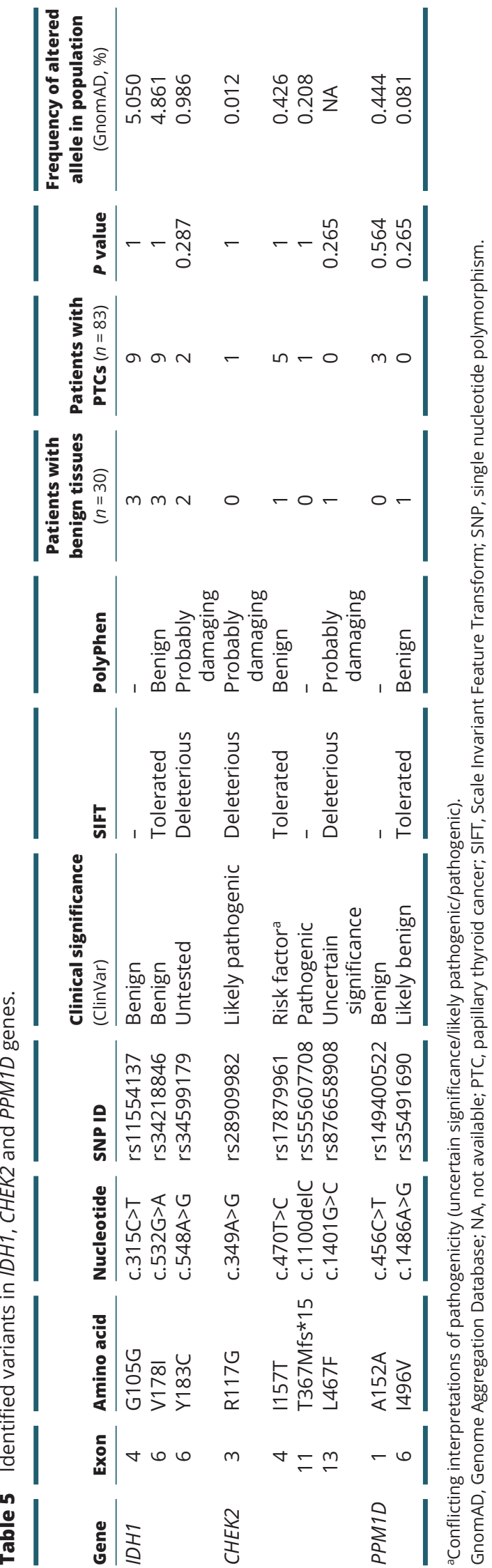

https://ec.bioscientifica.com

https://doi.org/10.1530/EC-19-0069

(c) 2019 The authors Published by Bioscientifica Ltd
The RET/PTC rearrangement was the most frequent mutation in our cohort of pediatric PTCs, detected in $18 / 83$ malignant samples exclusively. The prevalence of RET/PTC in pediatric PTCs is worldwide in the range of $15-67 \%(7,8,26,27)$. However, these fusion genes were also found in benign pediatric samples (28). RET/PTC is commonly associated with radiation-induced PTC, in which the prevalence is higher (7). In our study, all RET/PTC-positive patients were without radiation history. In literature, RET/PTC rearrangements do not harbor in general other driver co-mutation in the BRAF or RAS genes, which was also confirmed in our study. This co-occurrence was found only in few cases and it was associated with more aggressive disease $(8,29)$. RET/PTC-positive samples were associated (not statistically significant) with a higher rate of tumor growth (mostly T3/T4 classification), more frequent extrathyroidal extension, intravascular invasion and multifocality compared to BRAF-positive samples. They were significantly associated with more frequent local and distant metastases, especially in cases of RET/PTC3 rearrangement. No patient underwent reoperation due to recurrent metastases.

The BRAF V600E mutation was completely associated with PTC. In our cohort of pediatric PTCs, the prevalence of the BRAF V600E was $15 / 83$, which falls within the range of $0-63 \%$ of the prevalence $B R A F$ mutation in pediatric cases published earlier $(7,9,30,31)$. Possible reasons for wide dispersal of prevalence are different used methods, geographical and environmental factors, size of cohort and age border of pediatric patients. Our study also confirmed that the BRAF mutation correlates with the classical variant of PTC and the higher age of patients (32). The association of the BRAF V600E mutation with more frequent T1/T2 classification than T3/T4 classification and with higher rate of recurrence was seen, but was not statistically significant (Table 4). $B R A F$ V600E-positive patients had more lymph node metastases reoperations due to radiorefracterity than RET/PTC-positive patients, but the difference was not statistically significant.

In the IDH1 gene, the germline variants G105G and V178I in similar frequencies in patients with benign and malignant nodules were found. Clinical significance of these variants seems according to ClinVar database and SIFT/PolyPhen in silico analysis benign on thyroid tumorigenesis. The Y183C variant was detected with higher frequency in benign nodules. However, this variant was assumed as deleterious/probably damaging by SIFT and PolyPhen analysis. Clinical effect of Y183C variant is still unknown. None of the previously described variants

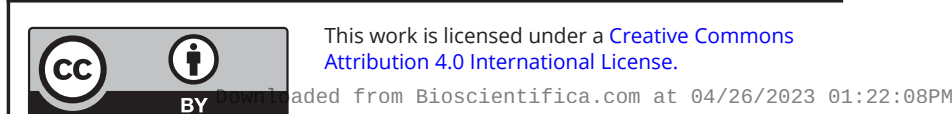


around codon R132 was found, where the active site of the enzyme occurs (14).

In the TCGA study PTC-causing somatic mutations in CHEK2, PPM1D and EIF1AX genes were identified. Our study revealed several variants in CHEK2 and PPM1D genes that were detected in benign as well as in malignant nodules. These variants did not correspond to those found in the TCGA study (13). All our detected variants in the CHEK2 and PPM1D genes were germline. I157T variant in the CHEK2 gene was detected in one benign tissue and in five PTCs, which falls in the worldwide range $4.5-15.6 \%$ of PTC $(33,34,35)$. It was reported that this variant increases the risk of PTC almost twice $(\mathrm{OR}=1.81)$ (35). In PTCs, also other variants R117G and T367Mfs*15 in the CHEK2 gene with probably deleterious effect on protein function were detected (36). It was published that truncating variants are associated with higher risk of thyroid cancer $(\mathrm{OR}=5.7)$ than $\mathrm{I} 157 \mathrm{~T}$ missense variants $(\mathrm{OR}=2.8)$ (34). In the PPM1D gene two variants were detected in our cohorts with probably benign significance on thyroid tumorigenesis. In our study, any variant in the EIF1AX gene was revealed. Frequency of mutations in this gene is generally very low and we assume according to our results, that there is probably no correlation between pediatric thyroid nodules and EIF1AX mutations. In one recent study, these novel genes were investigated in pediatric and adult cohorts with PTCs. In pediatric patients, they detected five variants in the CHEK2 gene, which were presented in all samples, two variants in the PPM1D gene and none in the EIF1AX gene. Found variants in the PPM1D gene did not match ours (37).

Any mutation in the TERT promoter in pediatric PTCs was detected. Mutations in this gene are strongly associated with the higher age of adult patients (38). In many studies of pediatric PTC, mutation in the TERT promoter has not yet been detected all over the world $(9,19)$, except one study. They found C228T mutation in 10-year-old patient without extrathyroidal invasion and metastases (39).

In the EZH1 gene, no mutation was found in benign and malignant specimens in our cohorts. The reason was probably a small cohort of benign samples, because mutations in the EZH1 gene were detected almost 20 times more frequently (13.5 vs $0.7 \%$ ) in benign than in malignant thyroid nodules (16). Mutations in the EZH1 gene were identified only in two PTC cases in the TCGA study (13).

In summary, we revealed genetic cause in 5/30 of benign nodules and in 35/83 of pediatric PTCs; mutations in the BRAF gene, RAS genes and RET/PTC rearrangements were included. There were significant differences in clinical courses in RET/PTC and BRAF-positive PTC patients. Patients with RET/PTC had more aggressive disease (more frequent local and distant metastases) than patients with $B R A F$ mutation. On the basis of the known genetic change in tumor, it could be possible to stratify and individualize the treatment. The role of $R A S$ mutations, especially in benign lesions, is not yet fully understood, so it should be kept in mind that they may predispose to cancer and the intensive follow-up of these patients is recommended. Some of the identified variants in the CHEK2 gene are pathogenic or likely pathogenic and the influence of found variants in the IDH1 and PPM1D gene on thyroid nodules is still uncertain and probably benign.

The genetic landscape of more than half of our PTC cases is still unknown; therefore, further investigation is required, for example in PTEN or PIK3CA genes, in which somatic mutations in pediatric PTCs were detected (22). Furthermore, other fusion genes need to be identified by RNA sequencing, and copy number variants should also be detected, which could be another trigger of thyroid cancer. The genetic molecular testing seems to be the benefit for pediatric patients for their diagnosis and prognosis. Hopefully, it will improve the quality of life of pediatric patients with thyroid nodules.

\section{Declaration of interest}

The authors declare that there is no conflict of interest that could be perceived as prejudicing the impartiality of the research reported.

\section{Funding}

This work was supported by the Ministry of Health of the Czech Republic AZV (16-32665A) grants.

\section{References}

1 Hogan AR, Zhuge Y, Perez EA, Koniaris LG, Lew JI \& Sola JE. Pediatric thyroid carcinoma: incidence and outcomes in 1753 patients. Journal of Surgical Research 2009156 167-172. (https://doi.org/10.1016/j. jss.2009.03.098)

2 Niedziela M. Pathogenesis, diagnosis and management of thyroid nodules in children. Endocrine-Related Cancer 200613 427-453. (https://doi.org/10.1677/erc.1.00882)

3 Vigneri R, Malandrino P \& Vigneri P. The changing epidemiology of thyroid cancer: why is incidence increasing? Current Opinion in Oncology 201527 1-7. (https://doi.org/10.1097/ CCO.0000000000000148)

4 Francis GL, Waguespack SG, Bauer AJ, Angelos P, Benvenga S, Cerutti JM, Dinauer CA, Hamilton J, Hay ID, Luster M, et al. Management guidelines for children with thyroid nodules and differentiated thyroid cancer. Thyroid 201525 716-759. (https://doi. org/10.1089/thy.2014.0460)

5 Mitsutake N, Fukushima T, Matsuse M, Rogounovitch T, Saenko V, Uchino S, Ito M, Suzuki K, Suzuki S \& Yamashita S. BRAFV600E 
mutation is highly prevalent in thyroid carcinomas in the young population in Fukushima: a different oncogenic profile from Chernobyl. Scientific Reports 20155 16976. (https://doi.org/10.1038/ srep16976)

6 Mon R \& Newlon J. Anaplastic carcinoma of the thyroid in a 12-year old girl. Journal of Pediatric Surgery Case Reports 20153 404-406. (https://doi.org/10.1016/j.epsc.2015.08.004)

7 Cordioli MICV, Moraes L, Cury AN \& Cerutti JM. Are we really at the dawn of understanding sporadic pediatric thyroid carcinoma? Endocrine-Related Cancer 201522 R311-R324. (https://doi. org/10.1530/ERC-15-0381)

8 Gertz RJ, Nikiforov Y, Rehrauer W, McDaniel L \& Lloyd RV. Mutation in BRAF and other members of the MAPK pathway in papillary thyroid carcinoma in the pediatric population. Archives of Pathology and Laboratory Medicine 2016140 134-139. (https://doi.org/10.5858/ arpa.2014-0612-OA)

9 Oishi N, Kondo T, Nakazawa T, Mochizuki K, Inoue T, Kasai K, Tahara I, Yabuta T, Hirokawa M, Miyauchi A, et al. Frequent BRAF $\mathrm{V} 600 \mathrm{E}$ and absence of tert promoter mutations characterize sporadic pediatric papillary thyroid carcinomas in Japan. Endocrine Pathology 201728 103-111. (https://doi.org/10.1007/s12022-017-9470-y)

10 Hay ID, Gonzalez-Losada T, Reinalda MS, Honetschlager JA, Richards ML \& Thompson GB. Long-term outcome in 215 children and adolescents with papillary thyroid cancer treated during 1940 through 2008. World Journal of Surgery 201034 1192-1202. (https:// doi.org/10.1007/s00268-009-0364-0)

11 Penko K, Livezey J, Fenton C, Patel A, Nicholson D, Flora M, Oakley K, Tuttle RM \& Francis G. BRAF mutations are uncommon in papillary thyroid cancer of young patients. Thyroid 200515 320-325. (https://doi.org/10.1089/thy.2005.15.320)

12 Borre PV, Schrock AB, Anderson PM, Morris JC, Heilmann AM, Holmes O, Wang K, Johnson A, Waguespack SG, Ou SI, et al. Pediatric, adolescent, and young adult thyroid carcinoma harbors frequent and diverse targetable genomic alterations, including kinase fusions. Oncologist 201722 255-263. (https://doi.org/10.1634/ theoncologist.2016-0279)

13 Cancer Genome Atlas Research Network. Integrated genomic characterization of papillary thyroid carcinoma. Cell 2014159 676-690. (https://doi.org/10.1016/j.cell.2014.09.050)

14 Hemerly JP, Bastos AU \& Cerutti JM. Identification of several novel non-p. R132 IDH1 variants in thyroid carcinomas. European Journal of Endocrinology 2010163 747-755. (https://doi.org/10.1530/EJE-100473)

15 Calebiro D, Grassi ES, Eszlinger M, Ronchi CL, Godbole A, Bathon K, Guizzardi F, De Filippis T, Krohn K, Jaeschke H, et al. Recurrent EZH1 mutations are a second hit in autonomous thyroid adenomas. Journal of Clinical Investigation 2016126 3383-3388. (https://doi. org/10.1172/JCI84894)

16 Jung CK, Kim Y, Jeon S, Jo K, Lee S \& Bae JS. Clinical utility of EZH1 mutations in the diagnosis of follicular-patterned thyroid tumors. Human Pathology 201881 9-17. (https://doi.org/10.1016/j. humpath.2018.04.018)

17 Dvorakova S, Sykorova V, Vaclavikova E, Sykorova P, Vlcek P, Kodetova D, Lastuvka P, Betka J, Mokrejs M, Vcelak J, et al. A 3-bp deletion VK600-1E in the BRAF gene detected in a young woman with papillary thyroid carcinoma. Endocrine Pathology 201526 309-314. (https://doi.org/10.1007/s12022-015-9387-2)

18 Halkova T, Dvorakova S, Vaclavikova E, Sykorova V, Vcelak J, Sykorova P, Vlcek P, Reboun M, Katra R, Kodetova D, et al. A novel RET/PTC variant detected in a pediatric patient with papillary thyroid cancer without ionization history. Human Pathology 201546 1962-1969. (https://doi.org/10.1016/j.humpath.2015.08.013)

19 Ballester LY, Sarabia SF, Sayeed H, Patel N, Baalwa J, Athanassaki I, Hernandez JA, Fang E, Quintanilla NM, Roy A, et al. Integrating molecular testing in the diagnosis and management of children with thyroid lesions. Pediatric and Developmental Pathology 201619 94-100. (https://doi.org/10.2350/15-05-1638-OA.1)

20 Picarsic JL, Buryk MA, Ozolek J, Ranganathan S, Monaco SE, Simons JP, Witchel SF, Gurtunca N, Joyce J, Zhong S, et al. Molecular characterization of sporadic pediatric thyroid carcinoma with the DNA/RNA ThyroSeq v2 next-generation sequencing assay. Pediatric and Developmental Pathology 201619 115-122. (https://doi. org/10.2350/15-07-1667-OA.1)

21 Eszlinger M, Niedziela M, Typlt E, Jaeschke H, Huth S, Schaarschmidt J, Aigner T, Trejster E, Krohn K, Bösenberg E, et al. Somatic mutations in 33 benign and malignant hot thyroid nodules in children and adolescents. Molecular and Cellular Endocrinology 2014 393 39-45. (https://doi.org/10.1016/j.mce.2014.05.023)

22 Alzahrani AS, Murugan AK, Qasem E, Alswailem M, Al-Hindi H \& Shi Y. Single point mutations in pediatric differentiated thyroid cancer. Thyroid 201727 189-196. (https://doi.org/10.1089/ thy.2016.0339)

23 Mostoufi-Moab S, Labourier E, Sullivan L, LiVolsi V, Li Y, Xiao R, Beaudenon-Huibregtse S, Kazahaya K, Adzick NS, Baloch Z, et al. Molecular testing for oncogenic gene alterations in pediatric thyroid lesions. Thyroid 201828 60-67. (https://doi.org/10.1089/ thy.2017.0059)

24 Patel SG, Carty SE, McCoy KL, Ohori NP, LeBeau SO, Seethala RR, Nikiforova MN, Nikiforov YE \& Yip L. Preoperative detection of RAS mutation may guide extent of thyroidectomy. Surgery $2017 \mathbf{1 6 1}$ 168-175. (https://doi.org/10.1016/j.surg.2016.04.054)

25 Kato S, Lippman SM, Flaherty KT \& Kurzrock R. The conundrum of genetic 'drivers' in benign conditions. Journal of the National Cancer Institute 2016108 djw036. (https://doi.org/10.1093/jnci/djw036)

26 Bongarzone I, Fugazzola L, Vigneri P, Mariani L, Mondellini P, Pacini F, Basolo F, Pinchera A, Pilotti S \& Pierotti MA. Age-related activation of the tyrosine kinase receptor protooncogenes RET and NTRK1 in papillary thyroid carcinoma. Journal of Clinical Endocrinology and Metabolism 199681 2006-2009. (https://doi. org/10.1210/jcem.81.5.8626874)

27 Fenton CL, Lukes Y, Nicholson D, Dinauer CA, Francis GL \& Tuttle RM. The ret/PTC mutations are common in sporadic papillary thyroid carcinoma of children and young adults. Journal of Clinical Endocrinology and Metabolism 200085 1170-1175. (https://doi. org/10.1210/jcem.85.3.6472)

28 Elisei R, Romei C, Vorontsova T, Cosci B, Veremeychik V, Kuchinskaya E, Basolo F, Demidchik EP, Miccoli P, Pinchera A, et al. RET/PTC rearrangements in thyroid nodules: studies in irradiated and not irradiated, malignant and benign thyroid lesions in children and adults. Journal of Clinical Endocrinology and Metabolism 200186 3211-3216. (https://doi.org/10.1210/jcem.86.7.7678)

29 Zou M, Baitei EY, Alzahrani AS, BinHumaid FS, Alkhafaji D, Al-Rijjal RA, Meyer BF \& Shi Y. Concomitant RAS, RET/PTC, or BRAF mutations in advanced stage of papillary thyroid carcinoma. Thyroid 201424 1256-1266. (https://doi.org/10.1089/ thy.2013.0610)

30 Henke LE, Perkins SM, Pfeifer JD, Ma C, Chen Y, DeWees T \& Grigsby PW. BRAF V600E mutational status in pediatric thyroid cancer. Pediatric Blood and Cancer 201461 1168-1172. (https://doi. org/10.1002/pbc.24935)

31 Kumagai A, Namba H, Saenko VA, Ashizawa K, Ohtsuru A, Ito M, Ishikawa N, Sugino K, Ito K, Jeremiah S, et al. Low frequency of BRAF T1796A mutations in childhood thyroid carcinomas. Journal of Clinical Endocrinology and Metabolism 200489 4280-4284. (https:// doi.org/10.1210/jc.2004-0172)

32 Nikita ME, Jiang W, Cheng SM, Hantash FM, McPhaul MJ, Newbury RO, Phillips SA, Reitz RE, Waldman FM \& Newfield RS. Mutational analysis in pediatric thyroid cancer and correlations with age, ethnicity, and clinical presentation. Thyroid 201626 227-234. (https://doi.org/10.1089/thy.2015.0401)

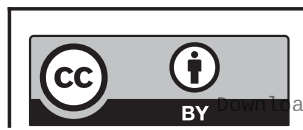

This work is licensed under a Creative Commons Attribution 4.0 International License. ded from Bioscientifica.com at 04/26/2023 01:22:08PM 
33 Cybulski C, Gorski B, Huzarski T, Masojć B, Mierzejewski M, Dębniak T, Teodorczyk U, Byrski T, Gronwald J, Matyjasik J, et al. CHEK2 is a multiorgan cancer susceptibility gene. American Journal of Human Genetics 200475 1131-1135. (https://doi. org/10.1086/426403)

34 Siołek M, Cybulski C, Gąsior-Perczak D, Kowalik A, Kozak-Klonowska B, Kowalska A, Chłopek M, Kluźniak W, Wokołorczyk D, Pałyga I, et al. CHEK 2 mutations and the risk of papillary thyroid cancer. International Journal of Cancer 2015137 548-552. (https://doi.org/10.1002/ijc.29426)

35 Kaczmarek-Ryś M, Ziemnicka K, Hryhorowicz ST, Górczak K, Hoppe-Gołębiewska J, Skrzypczak-Zielińska M, Tomys M, Gołąb M, Szkudlarek M, Budny B, et al. The c.470T>C CHEK2 missense variant increases the risk of differentiated thyroid carcinoma in the Great Poland population. Hereditary Cancer in Clinical Practice 201513 8. (https://doi.org/10.1186/s13053-0150030-5)
36 Desrichard A, Bidet Y, Uhrhammer N \& Bignon YJ. CHEK2 contribution to hereditary breast cancer in non-BRCA families. Breast Cancer Research 201113 R119. (https://doi.org/10.1186/bcr3062)

37 Alzahrani AS, Murugan AK, Qasem E, Alswailem MM, AlGhamdi B, Moria Y \& Al-Hindi H. Absence of EIF1AX, PPM1D, and CHEK2 mutations reported in thyroid Cancer Genome Atlas (TCGA) in a large series of thyroid cancer. Endocrine 201863 94-100. (https://doi. org/10.1007/s12020-018-1762-6)

38 Xing M, Liu R, Liu X, Murugan AK, Zhu G, Zeiger MA, Pai S \& Bishop J. BRAF V600E and tert promoter mutations cooperatively identify the most aggressive papillary thyroid cancer with highest recurrence. Journal of Clinical Oncology 201432 2718-2726. (https:// doi.org/10.1200/JCO.2014.55.5094)

39 Alzahrani AS, Qasem E, Murugan AK, Al-Hindi HN, AlKhafaji D, Almohanna M, Xing M, Alhomaidah D \& AlSwailem M. Uncommon tert promoter mutations in pediatric thyroid cancer. Thyroid 201626 235-241. (https://doi.org/10.1089/thy.2015.0510)

Received in final form 2 May 2019

Accepted 14 May 2019

Accepted Preprint published online 14 May 2019

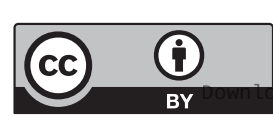

This work is licensed under a Creative Commons Attribution 4.0 International License.

ded from Bioscientifica.com at 04/26/2023 01:22:08PM 